\title{
Review of Team Member Exchange and Its Impact Mechanism
}

\author{
Min Wang ${ }^{a}$, Qingquan Pan ${ }^{b}$ \\ Guangxi University of Science and Technology, Liuzhou 545006, China; \\ a1012695596@qq.com, b471192309@qq.com
}

Keywords: Leader-member Exchange, Team- member Exchange, Social Exchange Theory.

\begin{abstract}
Today, more and more organizations rely on the form of the team to improve performance, then how to improve team performance has become a hot topic of current research. Based on the theory of social exchange, this article extends to the team level based on the theory of leadership exchange. Through the analysis of literature at home and abroad, this paper analyzes how the exchange of team members can improve the performance of the team or organization, with a view to providing some suggestions for future team research.
\end{abstract}

\section{Introduction}

Uncertainty in the external market environment allows companies to adopt more team-based innovation and improve organizational performance (Mathieu, Maynard, Rapp, \& Gilson, 2008). Graen et al. (1975) proposed a Leader-member exchange (LMX) based on social exchange theory. Seers (1989) argues that LMX theory only focuses on the vertical relationship between supervisors and supervisors in an organization, neglects the horizontal exchange relationship among colleagues, and the horizontal exchange relationship in a team is more important to the team members and the result of the team Therefore, scholars extend the social exchange relationship to the team level and propose a new concept of team member exchange (TMX).

Domestic scholars Sun Rui and Wang Naijing (2009) started from the concept of TMX proposed by Seers et al. That TMX reflects the quality of work relationships and team interdependencies among team members. Zou and Liu (2011) Empirical studies also found that the quality of the relationships exchanged among team members can affect teams and individuals, respectively, such as the team climate, the attitude and behavior of individual members, and they also consider TMX as a measure of team membership An Important Factor in the Quality of Relationships (Sun Rui and Wang Naijing, 2009).

However, there are differences in the quality of TMX due to the different content and processes exchanged among members. For example, low-quality TMX is only needed to fulfill the task assigned by the team leader, and high-quality TMX In addition, there are also intervening and exchanging emotions among team members such as mutual respect and trust. Therefore, exploring the impact of TMX on team building is of great importance (Witt et al., 2006).

\section{Relevant Overview of TMX}

\subsection{Section Headings.}

Sessions (1989) defined TMX as "the overall exchange between individual members of a team and other members of the team" that focuses on the quality of the working relationship among members of a team and the reciprocity exchange. Subsequently, Seers et al. (1995) further defined TMX as "the mutually beneficial relationship formed between members and other team members in terms of communication, information sharing, assisting others and obtaining help from others." At present, almost all the concepts of TMX are defined by the concepts of foreign scholars Seers (1989) and Seers et al. (1995). 


\subsection{TMX Dimension Division}

Tse et al. (2008) classify the two groups as task-oriented and relationship-oriented two types of exchange based on the content exchanged by team members. Task-oriented exchange is opinion feedback related to the completion of tasks, exchange of information resources, Guided exchanges are members' mutual trust, concern and much more. Li Shan-Gen and Ling-Wen Ling (2011) believe that TMX includes the acquisition of information resources and pay for two aspects, including access to members that are perceived to be honest with other members to share, when the work is relatively busy, take the initiative to help and so on; Individuals also honestly communicate with other members to share resources and also help others while they are busy.

\subsection{TMX Measurement Tools}

Seers (1989) first proposed three important measures of exchange and co-negotiation frequency and cohesion of TMX, and developed a proposal containing "I often give other colleagues a better working solution to the problem" 18 entries of the scale. Subsequent Seers et al.'s (1995) study divided TMX into payoffs and acquisitions of two measurement dimensions in the exchange process with the following entry: "I often help and encourage other colleagues in the team," with the entry: "Other Colleagues often help me, encourage me, "and finally there is a non-directional item to summarize the measure of TMX. The scale developed by Seers and other scholars as a whole has good reliability and validity, so most of the research on the exchange of team members follows the empirical study of the scale of these scholars.

\section{Factors affecting TMX}

\subsection{Workplace Friendship}

Workplace friendship is the willingness of employees to spend time with other members to maintain personal relationships other than their formal roles as co-workers (Sias, 2005; Sias \& Cahill, 1998). This voluntary interdependence helps in functions such as information sharing and decision-making, and provides team members with a tool for emotional support. Therefore, friendship is an important source of team support and intrinsic reward (Sias \& Cahill, 1998).

\subsection{Conflict Management Tendencies}

Conflict management tendencies refer to what kind of attitude the team members choose to handle a conflict when it occurs. Chen et al. (2015) found that in the face of conflict of work, co-operative management tend to adopt a collaborative approach; employees with competitive management tendencies tend to abandon the interests of others in order to satisfy their private interests, which is detrimental to team members The formation of exchange.

\subsection{Team Leadership Style}

Ko (2005) found that change leaders focus on increasing subordinates 'engagement with team goals, guiding employees to internalize team goals and work hard on teams, inspiring employees' creativity and increasing employee ownership of teams, identities and teams Satisfaction (Duan Jinyun and Huang Caiyun, 2014). Similarly, empirical studies by Xie Yizhong and Wu Ping (2017) also found that transformative leadership is more conducive to the exchange of team members.

\section{Efeect of TMX Mechanism}

\subsection{TMX Individual Level Result Variable}

Farth et al. (2017) proceeded from the resource contingency framework by integrating social exchange theory and social capital theory. The research found that only when the quality of resources provided by team members is high and the quality of resources provided by leaders is low, To have a more positive impact. Qi Dawei and Wu Xiaodan (2015) From the perspective of information theory, information sharing from teammates is an important solution to reduce the turnover rate of employees. Social network of employees can affect individual behavior from two aspects of information and emotional exchange. When an individual joins one In a group, its behavior necessarily affects other 
individuals in the group, so individuals with high turnover tendencies affect individuals in the group who have a good relationship with them (Gibbons, 2004).

\subsection{TMX Collective Level Result Variable}

According to Li Xue (2013), TMX is divided into two dimensions: team contribution and team achievement. The regression analysis shows that TMX has a positive positive impact on team performance. During the work process, the task information between members and emotion Exchange provides members with task-related support, feedback, and emotional recognition and help, achieving high team mission performance and high perimeter performance. High-quality TMX will be conducive to mutual respect, understanding and mutual psychology among team members. The resulting social support will enhance employees' team commitment, identity and self-achievement. Based on this, Sun Rui, Shi Jintao and Zhang Qin (2009) proposed a positive and positive relationship between the exchange of team members and the atmosphere of organizational innovation and have been verified.

\section{Conclusion and Future Prospect}

First, TMX drives research and development about how businesses operate at the team level. Managers can train the exchange relationships between co-workers and guide individuals how to express themselves in teams such as team management. Secondly, the high-quality TMX performance is the common goal of team members. Each member is willing to share the information resources, which helps to cultivate the trust, sense of responsibility and sense of cooperation among the members, which will reduce the team conflict, Improve team performance. Finally, high-quality TMX is an integral part of organizational innovation. Business leaders should pay attention to the interaction of team members, to provide staff with an open working environment, enhance the sense of belonging and responsibility of employees.

At present, most researches only discuss the influence of team members exchanging or leading members to exchange a certain variable on the team or organization based on the social exchange theory. In the future, we can explore the interaction between the two teams on the team or organization in order to better and deeply understand the theory of workplace exchange. However, in the Chinese situation characterized by "collectivism, Confucian culture and high power distance", whether the result of exchanging relations among team members still applies is also a future research direction. Finally, we explore the vertical development process of TMX deeply. The existing researches mostly focus on the influence of TMX on the team or organizational results. There are few systematic theoretical researches focusing on theoretical foundation and formation process.

\section{References}

[1]. Seers A. Team-Member Exchange Quality: A New Construct for Role-Making Research. Organizational Behavior \& Human Decision Processes [serial online]. February 1989;43(1):118.

[2]. Seers A, Petty M M, Cashman J F. Team-Member Exchange Under Team and Traditional ManagementA Naturally Occurring Quasi-Experiment[J]. Group \& Organization Management, 1995, 20(1):18-38.

[3]. Tse H H M, Dasborough M T, Ashkanasy N M. A multi-level analysis of team climate and

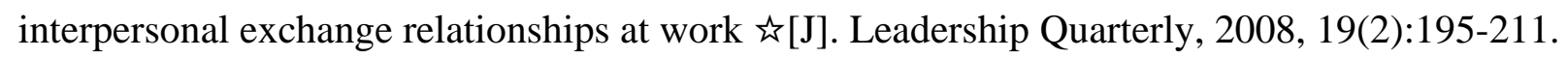

[4]. Ko J. Impact of leadership and team members' individualism-collectivism on team processes and outcomes: A leader-member exchange perspective[J]. 2005.

[5]. Witt L A, Hochwarter W A, Hilton T F, et al. Team-member exchange and commitment to a matrix team[J]. Journal of Social Behavior \& Personality, 1999, 14(1):63-74. 
[6]. Onne Janssen. The joint impact of perceived influence and supervisorsupportiveness on employee innovative behaviour[ J]. Journal of Occupational and Organizational Psychology,2005, 78, 573 579.

[7]. Graen G B, Scandura T A. Toward a psychology of dyadic organizing.[J]. Research in Organizational Behavior, 1987, 9(4):175-208.

[8]. Gibbons D E. Friendship and Advice Networks in the Context of Changing Professional Values[J]. Administrative Science Quarterly, 2004, 49(2):238-262.

[9]. Sun Rui, Shi Jintao, Zhang Tiqin. Chinese LMX, TMX, organizational innovation climate and Employee Innovative Behavior of empirical research on the relationship between [J]. management engineering, 2009,23 (04): 109-115.

[10]. Zou Wenchi, Liu Jia. In the team "I am for everyone, everyone is me" - team - member exchange research review [J]. psychological science progress, 2011,19 (08): 1193-1204.

[11]. Qi Dawei and Wu Xiaodan. Can mentors and friends retain employees? -- a cross cultural study of leaders' emotional intelligence and team member exchange on employee turnover intention [J]. China human resource development, 2015, (09): 56-61.

[12]. Chen Xiaomin, Chen Tongyang, Yu Yan. The impact of conflict management tendencies on team member exchange -- interpersonal trust as a mediator variable [J]. business economics research, 2015, (11): 110-112.

[13]. Sun Rui, Wang Naijing. Research on the relationship between team member exchange and organizational innovation of innovative enterprise group [J]. science research, 2009,27 (10): 1571-1575.

[14]. Li Shangen, Ling Wenquan. Research status and future prospects of foreign economic and management [J]. team member exchange, 2011,33 (07): 58-65.

[15]. Farh C I C, Lanaj K, Ilies R. Resource-based Contingencies of when Team-member Exchange Helps Member Performance in Teams[J]. Academy of Management Journal, 2016, 60(3):1117-1137.

[16]. Duan Jinyun, Huang Caiyun. The influence mechanism of transformational leadership on employee advice: the perspective of self determination [J]. Nankai management review, 2014,17 (04): 98-109.

[17]. Chan K W, Huang X, Peng M N. Managers' conflict management styles and employee attitudinal outcomes: The mediating role of trust[J]. Asia Pacific Journal of Management, 2008, 25(2):277-295. 